\title{
A WEBGIS FRAMEWORK FOR DISSEMINATING PROCESSED REMOTELY SENSED ON LAND COVER TRANSFORMATIONS
}

\author{
Grazia Caradonna', Antonio Novelli', Eufemia Tarantino', \\ Raffaela Cefalo ${ }^{2}$, Umberto Fratino ${ }^{1}$ \\ ${ }^{1}$ DICATECh, Politechnic of Bari, Via Orabona 4, 70125, BARI, Italy \\ ${ }^{2}$ GeoSNav Lab, University of Trieste, p.le Europa 1, 34127, TRIESTE, Italy
}

\begin{abstract}
Mediterranean regions have experienced significant soil degradation over the past decades. In this context, careful land observation using satellite data is crucial for understanding the long-term usage patterns of natural resources and facilitating their sustainable management to monitor and evaluate the potential degradation. Given the environmental and political interest on this problem, there is urgent need for a centralized repository and mechanism to share geospatial data, information and maps of land change. Geospatial data collecting is one of the most important task for many users because there are significant barriers in accessing and using data. This limit could be overcome by implementing a WebGIS through a combination of existing free and open source software for geographic information systems (FOSS4G).

In this paper we preliminary discuss methods for collecting raster data in a geodatabase by processing open multi-temporal and multi-scale satellite data aimed at retrieving indicators for land degradation phenomenon (i.e. land cover/land use analysis, vegetation indices, trend analysis, etc.). Then we describe a methodology for designing a WebGIS framework in order to disseminate information through maps for territory monitoring. Basic WebGIS functions were extended with the help of POSTGIS database and OpenLayers libraries. Geoserver was customized to set up and enhance the website functions developing various advanced queries using PostgreSQL and innovative tools to carry out efficiently multi-layer overlay analysis. The end-product is a simple system that provides the opportunity not only to consult interactively but also download processed remote sensing data.
\end{abstract}

Keywords: WebGIS, Satellite data, LU/LC, Vegetation analysis 


\section{Introduction}

Desertification is the persistent degradation of dryland ecosystems due to anthropogenic activities and variability in climate (Varghese \& Singh, 2016). Agenda 21, as approved by the United Nations Conference on Environment and Development (UNCED), defines desertification as "land degradation in arid, semi-arid and dry sub-humid areas resulting from various factors, including climatic variations and human activities"(Sombroek \& Sene, 1993). However, it's very difficult to distinguish the main cause (Meyer \& Turner, 1992). Nowadays, the phenomenon is considered as a major environmental issue for the $21^{\text {st }}$ century (Bank, 2003) because it reduces the soil fertility involving ecological and economic processes that characterize the environment at different geographic scales.

Several projects were developed all over the world to study and evaluate desertification. Among the projects funded by the European Commission, the MEDALUS Project (Mediterranean Desertification and Land-use) identified regions that are environmentally sensitive areas (ESAs) (Brandt \& Thornes, 1996; Kosmas, Kirkby, \& Geeson, 1999). Italy, together with Spain, Portugal and Greece, is one of the countries in Europe most affected by this phenomenon, mainly in some coastal areas of the southern regions (Puglia, Basilicata, Calabria), and on the main islands (Sicily and Sardinia) (Coscarelli, Caloiero, Minervino, \& Sorriso-Valvo, 2015). Land use and vegetation dynamics analyses demonstrated to be some of the key elements for its correct interpretation aimed at the sustainable management of environmental resources (Sepehr, Hassanli, Ekhtesasi, \& Jamali, 2007).

According to several studies, remote sensing can help in generating a significant amount of information needed to evaluate the vegetation cover distribution (Harris, Carr, \& Dash, 2014; Im et al., 2012; Muthumanickam et al., 2011), landscape degradation in arid and semiarid environments monitoring (Chen, Sakai, Moriya, Koyama, \& Cao, 2013) and the environmental change for desertification assessment (Lam, Remmel, \& Drezner, 2010; Weiers, Bock, Wissen, \& Rossner, 2004). Overlaying desertification severity maps interpreted from multi-temporal satellite imagery in a GIS platform (Liu, Gao, \& Yang, 2003) allows to accurately assess trend analysis thanks to continuous observations, thereby supporting the prediction and management of this problem (Han, Zhang, Zhang, \& Wan, 2015).

Some of the best methods available to quantify desertification are the assessment of loss of vegetation through vegetation indices analysis, i.e. the Normalized Vegetation Index (NDVI) and the Land Cover/Land Use (LULC) map interpretation. The Normalized Vegetation Index is the most usually used vegetation index (Tucker, 1979) to map spatial and temporal variation in vegetation (Lamchin et al., 2016). It varies in a range of -1 to +1 and it is provided from many satellite datasets at different spatial and time resolution. NDVI alone does not reflect drought or non-drought condition; it demonstrated its effectiveness in monitoring the desertification process if related to the environmental analysis.

Land Use/Land Cover maps are indispensable for further understanding of land change mechanism and modelling the impact of change on the environmental and associated ecosystem at different scales (Turner et al., 1995). Several methodologies can be used to generate LULC maps but some of them are expensive and generally not convenient for mapping large areas. Artificial neural networks (ANNs) behave as general pattern recognition systems and assume no prior statistical model for input data, so they represent an excellent technique to change 
detection analysis when no ground reference data are available for historic satellite imagery (Kavzoglu \& Mather, 2003; Zhang \& Foody, 2001).

Nevertheless, significant barriers in using satellite data for the interpretation of desertification phenomenon still persist, mainly due to difficulties in accessing and processing data.

Internet has become increasingly accessible and so the ways in which technicians seek data and information have changed dramatically over the years (Chang \& Caneday, 2012). Among the Internet applications, Web-based spatial data services (WebGIS) opened a new generation of information channels. WebGIS has the potential to share data, providing easy access for users with limited GIS knowledge (Soto-Garcia, Del-Amor-Saavedra, Martin-Gorriz, \& Martínez-Alvarez, 2013) and to assemble data and information customized for specific topics, supporting informed decision-making (Mathiyalagan, Grunwald, Reddy, \& Bloom, 2005) (Orellana, Del Sagrado, \& Del ÁGuila, 2011). Free Open Source Software (FOSS) are programs whose licenses give users the freedom to run and modify the program for any purpose. A comprehensive list of GIS-related FOSS can be found at http://opensourcegis.org/. According to Wheeler (1), FOSS reliability, performance, scalability, security and total cost of ownership are at least as good or better than its proprietary competition, and under certain circumstances, they are a superior alternative to their proprietary counterparts.

This study focuses on the development of a WebGIS to assist decision makers in monitoring land cover changes based on remote sensing and vector datasets. The system helps the user to get not only an overall picture of the study area with regard to the condition of vegetation over the cropping season but also warns against drought and other severe conditions. Multi-temporal LANDSAT satellite images were processed using the MLP feed-forward neural network method for the characterization of land use within two study areas of Foggia and Taranto (Apulia region, Italy). High temporal resolution satellite data (i. e SPOT VGT S10 NDVI) were selected to populate the WebGIS archive for a better interpretation of vegetation conditions and land cover transformations (Perovic et al., 2016; Sharma \& Mishra, 2012). The database was set up by using PostgreSQL and PostGIS as geographic extension. The system was designed using a suite of free and open source software (FOSS) that accomplished all the implementation requirements, including QGIS as Geographic Information Systems (GIS) software, Apache and Geoserver as web server and Mapfish framework with the two components Openlayers and ExtJS, on the client side.

\section{Data and methods}

Three different free available online datasets were downloaded for this work, respectively Landsat 5 and 7 scenes (Tab. 1-2), SPOT VGT NDVI time series for the period 1999 - 2013 and the Apulian Technical Cartography.

The chosen study area is Apulia Region (Southern Italy) (Fig. 1). In particular, the Normalized Vegetation Index (NDVI) maps had been shown for the whole region, while the LULC maps had been produced for two specific areas: Taranto province and Gargano area. Apulia is the most Eastern region of Italy overlooking the Adriatic and Ionian seas. The territory is mainly flat and hill. The greatest part of the territory $(81.4 \%)$ is used for agriculture while forestry and semi-natural areas cover about $13.3 \%$ of the region (Zalidis, Stamatiadis, Takavakoglou, Eskridge, \& Misopolinos, 2002; Van der Knijff, Jones, \& Montanarella, 2000). Water bodies cover about $1.2 \%$ 
of the territory including both natural lakes and artificial storage dams (Ladisa, Todorovic, \& Trisorio Liuzzi, 2012). The site is characterized by Mediterranean heterogeneous climate with strong inter-annual variability and a marked annual seasonality. Rainfall is distributed quite irregularly over the year with an average minimum value of about $600 \mathrm{~mm} / \mathrm{year}$ and peaks in the October-March semester (Balacco, Figorito, Tarantino, Gioia, \& lacobellis, 2015) even if in the last decades the extreme rain events are becoming more and more frequent.

LANDSAT data were downloaded from the USGS website (http://glovis.usgs.gov/) as Level 1 terrain corrected (L1T). The L1Tdata are available in GeoTiff format in WGS84 - UTM plane coordinates (Tarantino, Novelli, Aquilino, Figorito, \& Fratino, 2015; Tucker, 1979). Level T1 processing includes radiometric correction, systematic geometric correction, precision correction using ground control chips and the use of a digital parallax correction due to local topographic relief (Figorito, Mancini, Novelli, \& Tarantino, 2014).

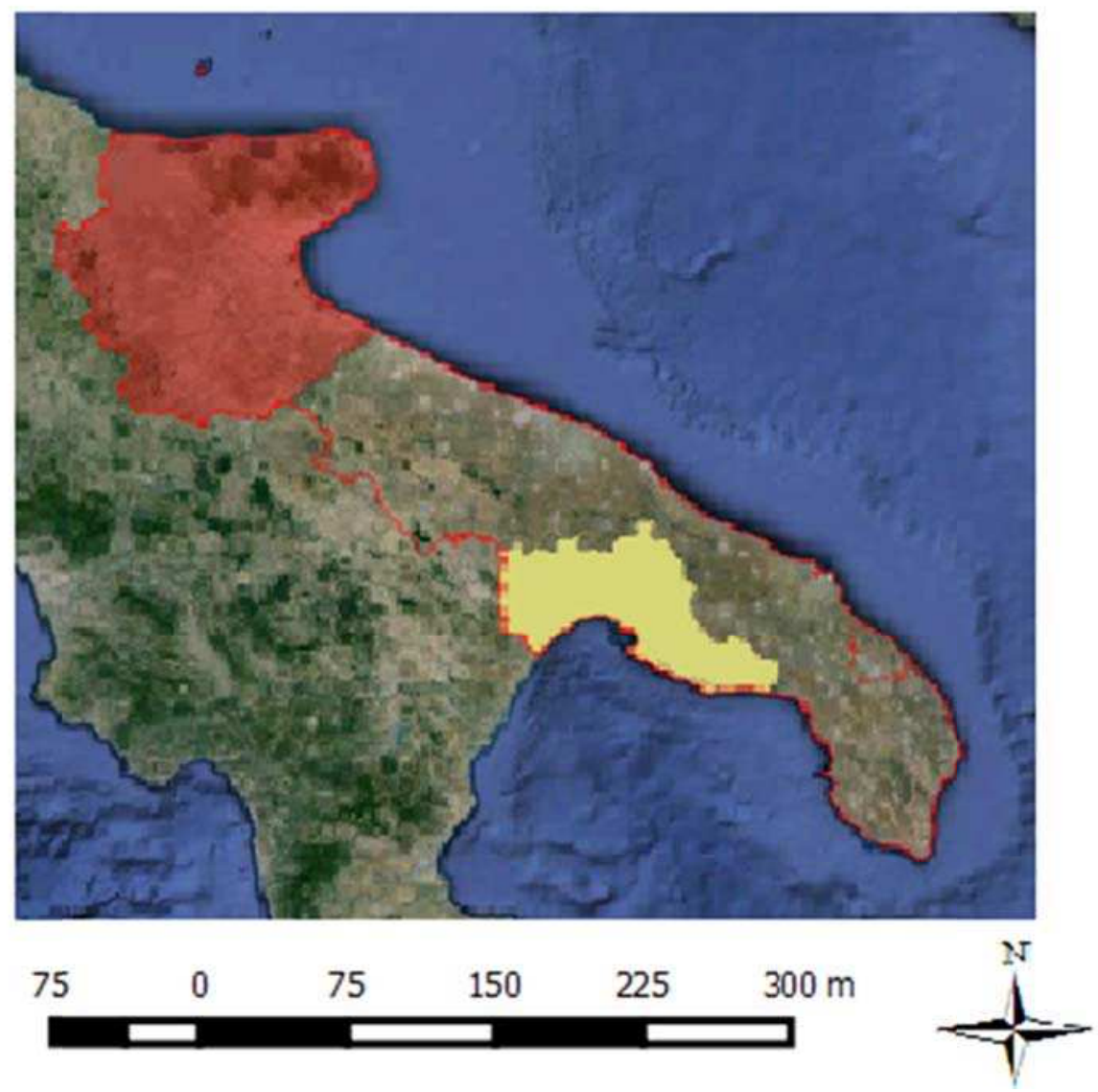

Fig. 1. The study area 
Tab. 1. LANDSAT 5-TM scenes used for LULC maps of Taranto province

\begin{tabular}{lllll}
\hline & Data & Sensor & $\begin{array}{l}\text { Cloud } \\
\text { cover \% }\end{array}$ & Quality \\
\hline LT51870321986234XXX01 & $22 / 08 / 1986 \mathrm{tm}$ & 0 & 9 \\
LT51870321987109AAA02 & $19 / 04 / 1987 \mathrm{tm}$ & 0 & 9 \\
LT51870322000241FUI00 & $28 / 08 / 2000 \mathrm{tm}$ & 0 & 9 \\
LT51870322003265MTI01 & $22 / 09 / 2003 \mathrm{tm}$ & 0 & 9 \\
LT51870322004236MTI00 & $23 / 08 / 2004 \mathrm{tm}$ & 0 & 9 \\
LT51870322009201MOR00 & $20 / 07 / 2009 \mathrm{tm}$ & 0 & 9 \\
LT51870322010236MOR00 & $24 / 08 / 2010 \mathrm{tm}$ & 0 & 9 \\
LT51870322011191MOR00 & $10 / 07 / 2011 \mathrm{tm}$ & 0 & 9 \\
\hline
\end{tabular}

Tab. 2. LANDSAT 5-TM scenes used for LULC maps of Gargano area

\begin{tabular}{lllll}
\hline Scene id & Data & Sensor & $\begin{array}{l}\text { Cloud } \\
\text { cover \% }\end{array}$ & Quality \\
\hline LT51890311984179XXX06 & $27 / 06 / 1984 \mathrm{tm}$ & 0 & 9 \\
LT51890311987139XXX03 & $19 / 05 / 1987 \mathrm{tm}$ & 0 & 9 \\
LT51890312003199MTI03 & $18 / 07 / 2003 \mathrm{tm}$ & 0 & 9 \\
LT51890312009167MOR00 & $16 / 06 / 2009 \mathrm{tm}$ & 0 & 9 \\
LT51890312011173MOR00 & $22 / 06 / 2011 \mathrm{tm}$ & 0 & 9 \\
\hline
\end{tabular}

\subsection{Satellite data processing}

Constructing an appropriate ANN model is a challenge for Land Cover/Land Use classification. Many crucial parameters, such as the number of hidden layers and hidden layer nodes, learning rates, momentum factor and training sites, have to be set up manually. The parameters have to be properly set up to find the global minimum of the error function instead of a local minimum. The number of hidden layer nodes has a significant impact on the classification accuracy. Too many hidden layer nodes will cause over-fitting of the model, while too few cannot identify the internal data structure (Hu \& Weng, 2009).

As first step, images were radiometrically corrected. Using the post-launch calibration coefficients, the related data on surface reflectivity were converted into absolute forms as reflectance. Next, following the mosaicing and resizing (spatial/spectral) procedures, an atmospheric correction was undertaken on each data set. Lastly, to prepare for change detection analysis on multi-date LANDSAT images, the homogenization in a unique digital information content was required (Tarantino et al., 2015; Tan, San Lim, MatJafri, \& Abdullah, 2012). In order to characterize thematic classes Minimum Mapping Units (MMU) of $900 \mathrm{~m}^{2}$ (pixel area) were processed for classification (Fig. 3). Technical and Land Use cartography of 2006 (scale 1: 5000) and Google Earth data updated to 2011 were used as ground truth information for detecting the Regions Of Interest (ROI). 
The same procedure was implemented to obtain LULC maps for the second study area. As shown in Tab. 2 data are all LANDSAT 5 data except 01/05/2001 ETM + data.

The NDVI satellite data used in this study came from two instruments, Vegetation 1 and Vegetation 2, onboard of SPOT 4 and SPOT 5 satellites for the period 19992013.

The VEGTATION (VGT) instrument includes four spectral bands in the blue, red, near infrared and shortwave-infrared spectral wavelengths: the red and NIR bands are usually used to characterize the vegetation and the blue band is used for atmospheric corrections. The orbit of the VGT sensor ensures daily global coverage of the Earth's surface with a 1-km footprint of the pixel in the ground. The Vlaamse Instelling voor Technologisch Onderzoek (VITO) routinely operates atmospheric and angular corrections of reflectance data from SPOT-4/ VGT-I and SPOT-5/VGTII, which results in two 10-day composite products (S10 and D10 data) delivered in a Plate Carrée projection (WGS84 ellipsoid), at a spatial resolution of $1 / 112^{\circ}$ (Maisongrande, Duchemin, \& Dedieu, 2004).

The acquisitions were compared pixel to pixel according to the criterion of maximum reflectance. To facilitate the publication of data on the WebGIS, it was necessary to transform the data set into the same map coordinates (WGS84 - UTM zone 33). Data were reprojected and resampled using a nearest neighbor operator within QGIS 2.8 software. The NDVI index was calculated for each pixel's digital number of each data using the linear relationship provided by VITO agency:

$$
N D V I(t)_{i j}=\left(D N(t)_{i j} \cdot a\right)+b
$$

where: $\boldsymbol{N D V I}(\boldsymbol{t})_{i j}$ and $\boldsymbol{D N}(\boldsymbol{t})_{i j}$ are the NDVI and DN at the time $\mathrm{t}$ and at ij coordinates; $\boldsymbol{a}=\mathbf{0 . 0 0 4}$;

$\boldsymbol{b}=-\mathbf{0 . 1}$.

The database was populated by Apulian Technical Cartography and external information sources using Web Map Services (WMS), such as OpenStreetMaps and National Institute of Statistics (ISTAT) maps.

\subsection{The WebGis architecture components and functions}

The opportunity to consult complete multi-temporal remote sensing datasets is a noteworthy advantage. In fact, finding satellite imagery by non-expert users is often more difficult than gathering other geospatial data: not everyone knows where to find them, website providers request registration and the whole may be very long-lasting process (Caradonna, Figorito \&Tarantino, 2015).

For these reasons, the current WebGIS application was developed paying attention to the following needs and peculiarities:

- large dimension raster maps visualization and management capabilities;

- optimal organization of cartographic resources for easy consultation;

- land use/land cover data maps download.

After comparing various popular WebGIS secondary development technologies, the following suite of Free Open Source Software was adopted in this case study (Fig. 2):

- QGIS 2.12.3 as GIS software;

- Apache 2.4 and Geoserver 2.8.3 as server and map server;

- Mapfish 1.2 as framework. 


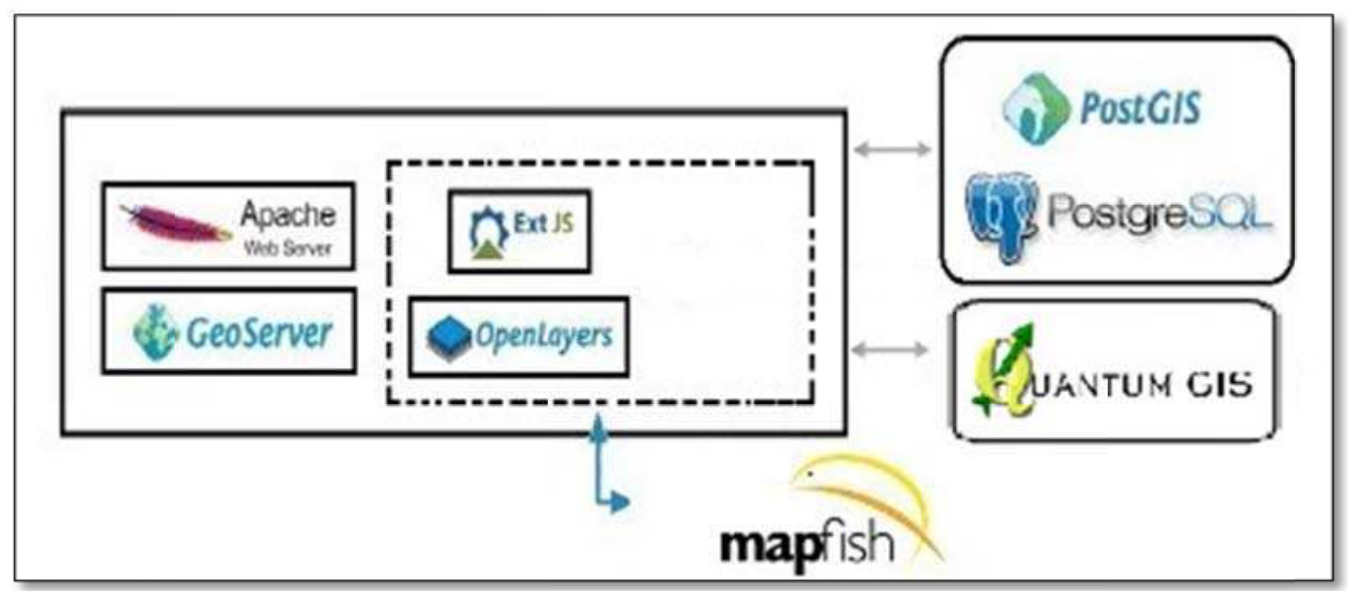

Fig. 2. WebGIS architecture.

The system collects a large quantity of heterogeneous data which can directly or indirectly be linked to a geographic location. For this purpose, PostgreSQL was chosen as object-relational DBMS to manage geographic data offering the function to process geometry and topology. It supports almost all SQL constructs, including subselections, transactions and user-defined types and functions. Lastly, its spatial extension PostGIS allows the use of PostgreSQL as a backend spatial database for Geographic Web-Based Spatial Information Solutions Information Systems.

User interaction was guaranteed by a client/server approach using standard HTTP language to provide a unique (therefore consistent) data repository and eliminate the need for the user to install special software to access the system (Simeoni, Floretta \& Zatelli 2011).

The webGIS server side uses Apache 2.0 as web server and Geoserver as WMS/WFS-T server following the OGC's standard for raster and vector maps. Geoserver plays the role of providing web map services for the client, receiving a unified, standardized WFS and WMS request and return to multiple data formats. Moreover, it facilitates the release of map data, allowing users to update and insert data characteristics. The OGC web service (OWS) process request is constituted by the following steps (Fig 4):

- Parsing the HTTP request parameters: the program translates them into the corresponding object.

- Matching the service object, choosing proper service according to the request parameters. In this case the services of the request are: http://localhost:8080/geoserver/ Webgis/ wms?service= WMS\&version=1.1.0 \&request $=$ GetMap\&layers $=$ Webgis:taranto_1986\&styles $=\& b b o x=$ $643335.0,4463475.0,737745.0,4519455.0$ \&width=768\& height=455\&srs= EPSG:32633\&format=application/openlayers.

- Executing the string org.geoserver.platform.Operation. The object uses Java reflection principle to implement the function call, so its need to create an array of function arguments.

- Returning the results to the client. 
The client side was written in JavaScript language using the Mapfish framework that combines OpenLayers and ExtJS (Simeoni, Zatelli \& Floretta, 2014). The browser locally executes it without installing any software. Both server and client parts were customized by means of new Java and PHP scripts. Through MapFish final users can display maps using WMS and WFS services by directly connecting to PostGIS DBMS. Some data layers, originally in ESRl's shapefile format, were converted to tables in the PostgreSQL RDBMS using SQL statements (Fig. 5 - 6). This conversion was achieved using the shp2pgsql utility included as part of the PostGIS extension, allowing the selection of data projection. The resulting table contains all the shapefile attributes and the coordinates that define each feature.

The prototype was implemented following the Open Geospatial Consortium and the European INSPIRE directive with a free and accessible source code.

The user interface was divided in two frames: on the left, layers are organized into themes with a legend, and on the right a map viewer was located (Fig. 7). The features provided through the WebGIS were categorized in two layer typologies: vector, raster and PostgreSQL data layers and WMS services.

The resulted interactive WebGIS system allows common qualitative analysis of land cover transformations through the visualization of LULC maps (Fig. 8). The information can be displayed in a dedicated pop-up balloon. For this purpose, the metadata requests were managed in the system through the CSW standard: in this way, the service returns an XML service for displaying the requested information.

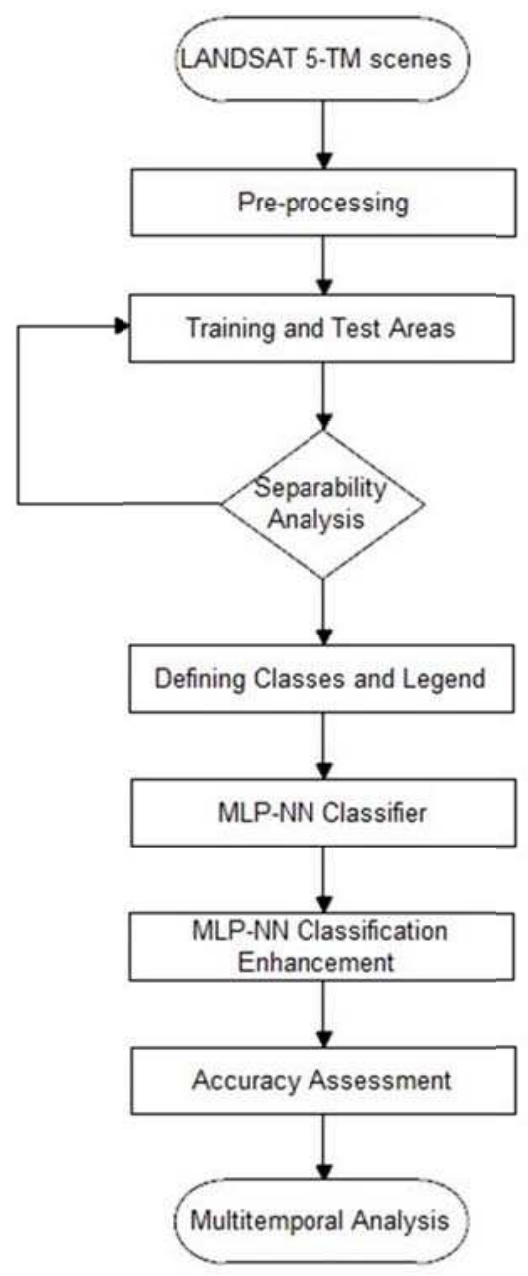

Fig. 3. Landsat data classification procedures

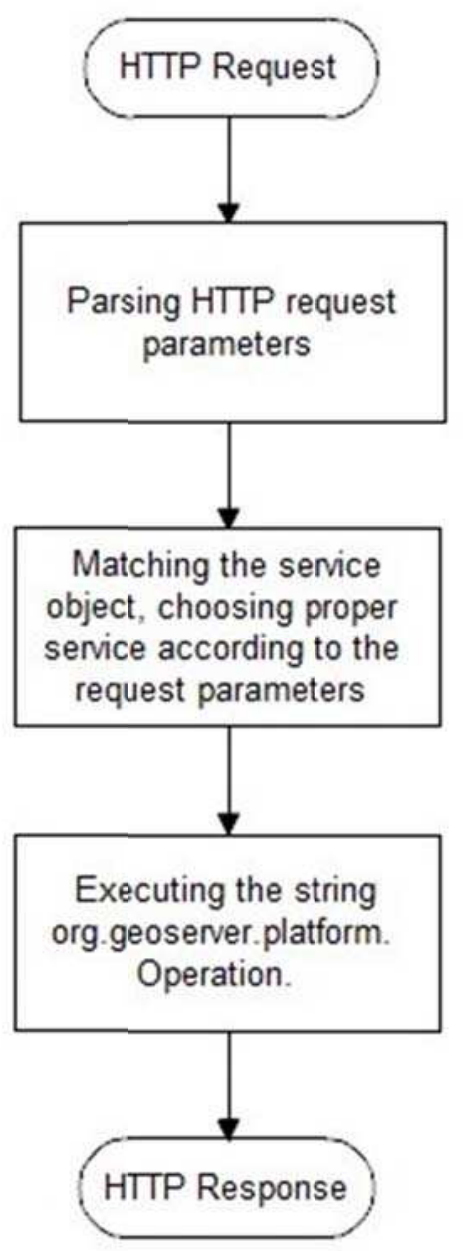

Fig. 4. Geoserver operating principle 


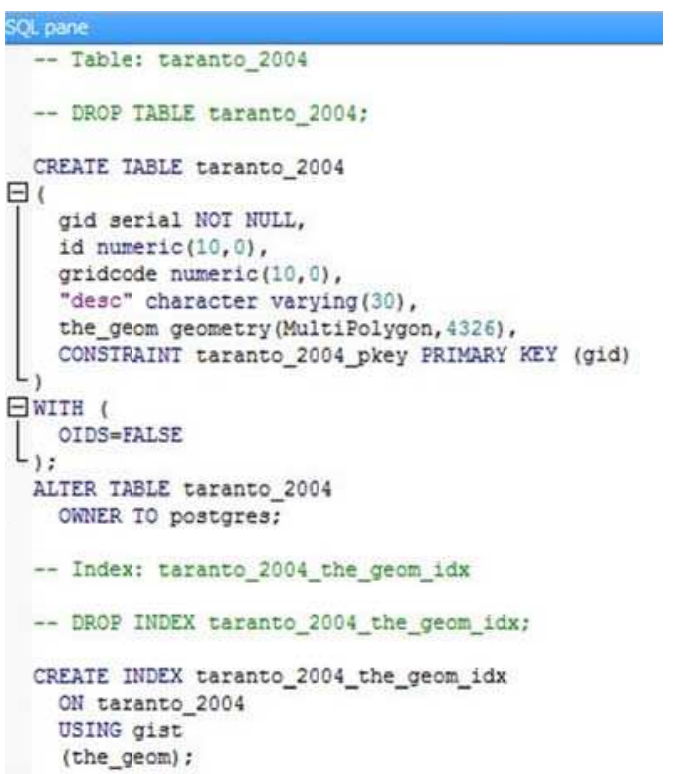

Fig. 5. SQL statements to create a table shapefile

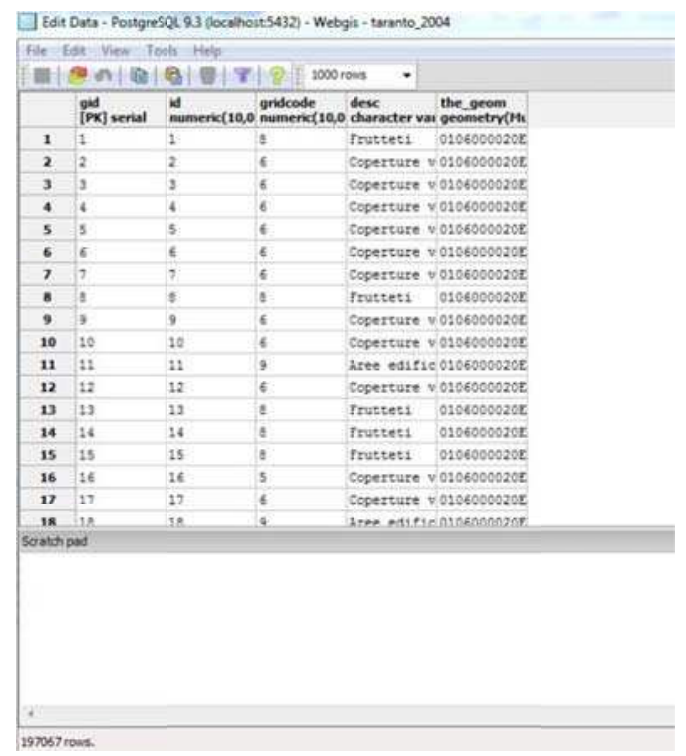

Fig. 6. Table representing

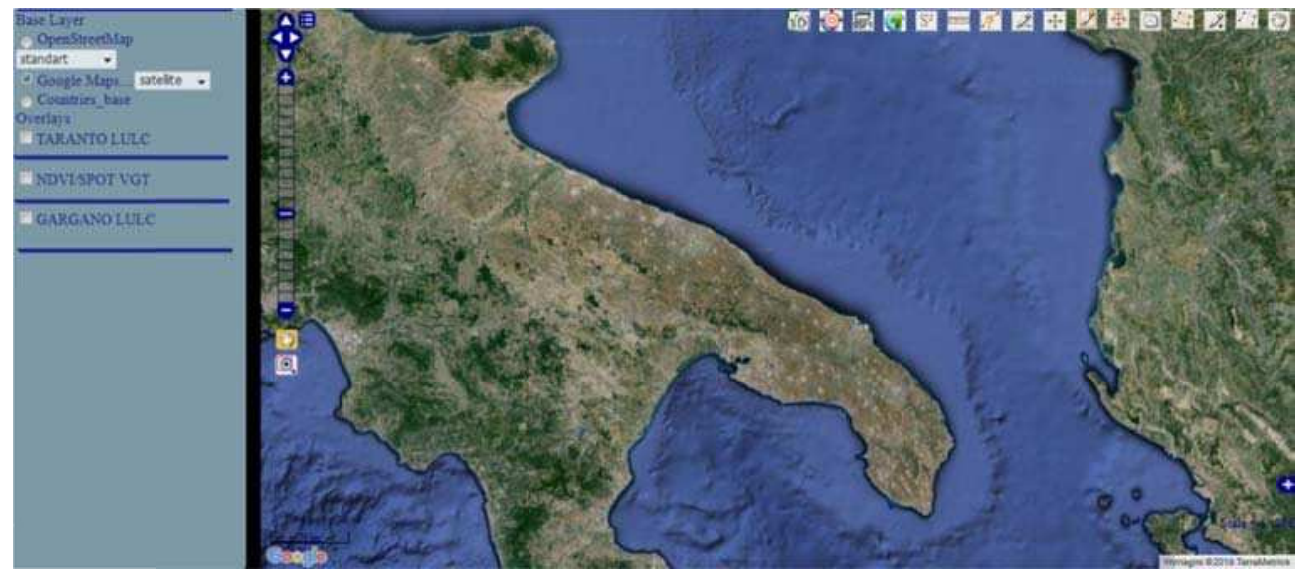

Fig. 7. WebGIS layout

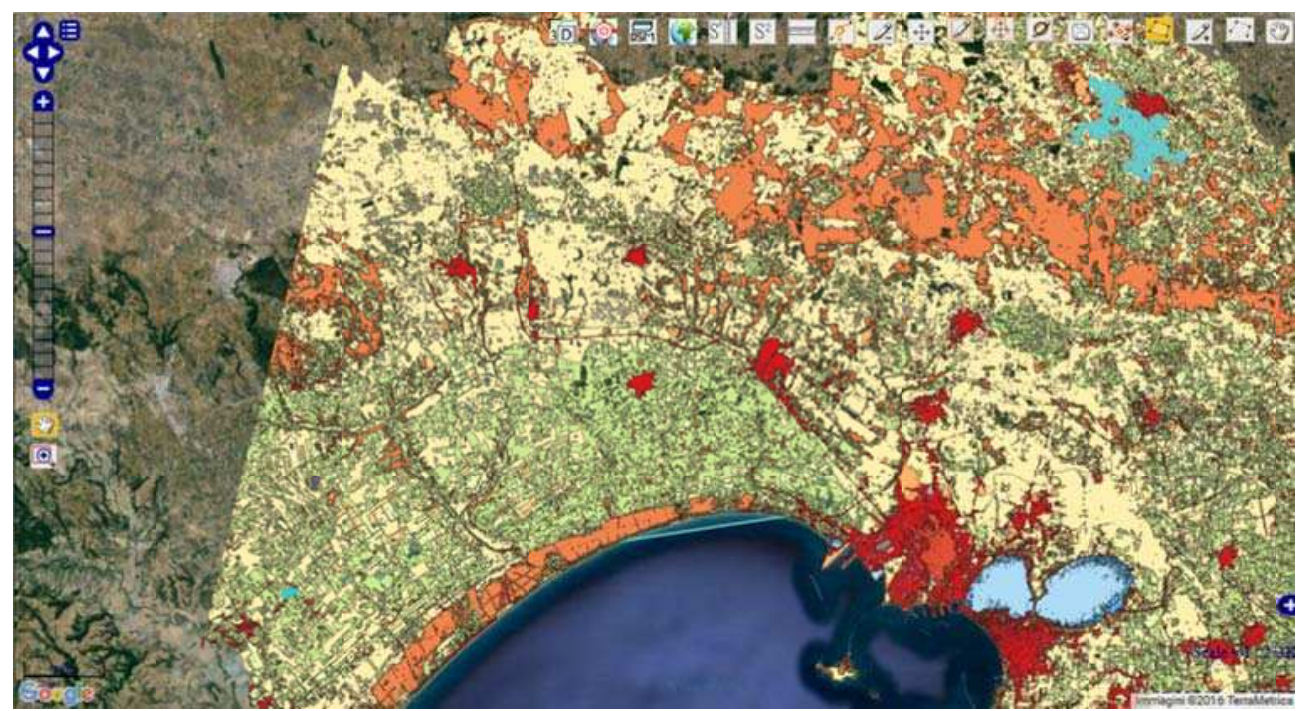

Fig. 8. Land Use /Land Cover of the Taranto territory 


\section{Discussion and Conclusions}

The aim of this work was to develop a WebGIS for the dissemination of processed satellite data in order to monitor the land cover transformations in the Apulia region (Italy). The system was realized using only free softwares. Integrating open source standards Web service based applications to build spatial information systems is a promising alternative to solutions based on commercial products and provide unrestricted access to useful information that can help public professionals and the technicians. The system permits interactive analysis of vector and raster data models thanks to MapFISH framework. Future developments are related to the implementation of tools for geo-processing raster and vector data on the web and real-time components for the management of environmental emergencies.

\section{References}

Balacco, G., Figorito, B., Tarantino, E., Gioia, A., \& lacobellis, V. (2015). Space-time LAI variability in Northern Puglia (Italy) from SPOT VGT data. Environmental Monitoring and Assessment, 187(7), 1-15.

Bank, W. (2003). Sustainable Development in a Dynamic World: Transforming Institutions, Growth, and Quality of Life: Oxford University Press.

Brandt, C. J., \& Thornes, J. B. (1996). Mediterranean desertification and land use: John Wiley \& Sons Ltd.

Caradonna, G., Figorito, B., \& Tarantino, E. (2015). Sharing Environmental Geospatial Data Through an Open Source WebGIS. In Computational Science and Its Applications--ICCSA 2015 (pp. 556-565). Springer International Publishing.

Chang, G., \& Caneday, L. (2012). Web-Based GIS in Tourism Information Search: An analysis of the effect of socioeconomic characteristics on perception and behavior. Loisir et Société/Society and Leisure, 35(1), 155-174.

Chen, W., Sakai, T., Moriya, K., Koyama, L., \& Cao, C. (2013). Estimation of vegetation coverage in semi-arid sandy land based on multivariate statistical modeling using remote sensing data. Environmental Modeling \& Assessment, 18(5), 547-558.

Coscarelli, R., Caloiero, T., Minervino, I., \& Sorriso-Valvo, M. (2015). Sensitivity to desertification of a high productivity area in Southern Italy. Journal of Maps, 1-9.

Figorito, B., Mancini, F., Novelli, A., \& Tarantino, E. (2014). Monitoring land cover changes at watershed scale using LANDSAT imagery. Score@Poliba.

Han, L., Zhang, Z., Zhang, Q., \& Wan, X. (2015). Desertification assessments in the Hexi corridor of northern China's Gansu Province by remote sensing. Natural Hazards, 75(3), 2715-2731.

Harris, A., Carr, A., \& Dash, J. (2014). Remote sensing of vegetation cover dynamics and resilience across southern Africa. International Journal of Applied Earth Observation and Geoinformation, 28, 131-139.

$\mathrm{Hu}$, X., \& Weng, Q. (2009). Estimating impervious surfaces from medium spatial resolution imagery using the self-organizing map and multi-layer perceptron neural networks. Remote Sensing of Environment, 113(10), 2089-2102. Retrieved from http://www.sciencedirect.com/science/article/pii/S0034425709001655

Im, J., Jensen, J. R., Jensen, R. R., Gladden, J., Waugh, J., \& Serrato, M. (2012). Vegetation cover analysis of hazardous waste sites in Utah and Arizona using hyperspectral remote sensing. Remote Sensing, 4(2), 327-353. 
Kavzoglu, T., \& Mather, P. (2003). The use of backpropagating artificial neural networks in land cover classification. International journal of remote sensing, 24(23), 4907-4938.

Kosmas, C., Kirkby, M. J., \& Geeson, N. (1999). The Medalus Project: Mediterranean Desertification and Land Use: Manual on Key Indicators of Desertification and Mapping Environmentally Sensitive Areas to Desertification: Directorate-General Science, Research and Development.

Ladisa, G., Todorovic, M., \& Trisorio Liuzzi, G. (2012). A GIS-based approach for desertification risk assessment in Apulia region, SE Italy. Physics and Chemistry of the Earth, Parts A/B/C, 49, 103-113.

doi:http://dx.doi.org/10.1016/j.pce.2011.05.007

Lam, D. K., Remmel, T. K., \& Drezner, T. D. (2010). Tracking Desertification in California Using Remote Sensing: A Sand Dune Encroachment Approach. Remote Sensing, 3(1), 1-13.

Lamchin, M., Lee, J.-Y., Lee, W.-K., Lee, E. J., Kim, M., Lim, C.-H., Kim, S.-R. (2016). Assessment of land cover change and desertification using remote sensing technology in a local region of Mongolia. Advances in Space Research, 57(1), 64-77.

Liu, Y., Gao, J., \& Yang, Y. (2003). A holistic approach towards assessment of severity of land degradation along the Great Wall in Northern Shaanxi Province, China. Environmental Monitoring and Assessment, 82(2), 187-202.

Maisongrande, P., Duchemin, B., \& Dedieu, G. (2004). VEGETATION/SPOT: an operational mission for the Earth monitoring; presentation of new standard products. International Journal of Remote Sensing, 25(1), 9-14.

Mathiyalagan, V., Grunwald, S., Reddy, K., \& Bloom, S. (2005). A WebGIS and geodatabase for Florida's wetlands. Computers and electronics in agriculture, 47(1), 69-75.

Meyer, W. B., \& Turner, B. L. (1992). Human population growth and global landuse/cover change. Annual review of ecology and systematics, 23, 39-61.

Muthumanickam, D., Kannan, P., Kumaraperumal, R., Natarajan, S., Sivasamy, R., \& Poongodi, C. (2011). Drought assessment and monitoring through remote sensing and GIS in western tracts of Tamil Nadu, India. International journal of remote sensing, 32(18), 5157-5176.

Orellana, F. J., Del Sagrado, J., \& Del ÁGuila, I. M. (2011). SAIFA: A web-based system for Integrated Production of olive cultivation. Computers and electronics in agriculture, 78(2), 231-237.

Perovic, V., Jaramaz, D., Zivotic, L., Cakmak, D., Mrvic, V., Milanovic, M., \& Saljnikov, E. (2016). Design and implementation of WebGIS technologies in evaluation of erosion intensity in the municipality of NIS (Serbia). Environmental Earth Sciences, 75(3), 1-12.

Sepehr, A., Hassanli, A., Ekhtesasi, M., \& Jamali, J. (2007). Quantitative assessment of desertification in south of Iran using MEDALUS method. Environmental Monitoring and Assessment, 134(1-3), 243-254. Retrieved from http://link.springer.com/article/10.1007\%2Fs10661-007-9613-6

Sharma, S. A., \& Mishra, S. (2012). Web-GIS based monitoring of vegetation using NDVI profiles. Journal of Geomatics, 6(2), 109-112.

Simeoni, L., Floretta, C., \& Zatelli, P. (2011). Spatial database and web-GIS for managing and validating river embankment monitoring data. In Proc. of the 8th International Symposium on Field Measurements in Geomechanics. 
Simeoni, L., Zatelli, P., \& Floretta, C. (2014). Field measurements in river embankments: validation and management with spatial database and webGIS.Natural hazards, 71(3), 1453-1473.

Sombroek, W., \& Sene, E. (1993). Land degradation in arid, semi-arid and dry subhumid areas: rainfed and irrigated lands, rangelands and woodlands. Paper presented at the Inter-Governmental Negotiating Committee for the Preparation of a Convention to Combat Desertification and Drought. Substantive Sess. 1, Nairobi (Kenya), 24 May-4 Jun 1993.

Soto-Garcia, M., Del-Amor-Saavedra, P., Martin-Gorriz, B., \& Martínez-Alvarez, V. (2013). The role of information and communication technologies in the modernisation of water user associations' management. Computers and electronics in agriculture, 98, 121-130.

Tan, K. C., San Lim, H., MatJafri, M. Z., \& Abdullah, K. (2012). A comparison of radiometric correction techniques in the evaluation of the relationship between LST and NDVI in Landsat imagery. Environmental monitoring and assessment, 184(6), 3813-3829.

Tarantino, E., Novelli, A., Aquilino, M., Figorito, B., \& Fratino, U. (2015). Comparing the MLC and JavaNNS Approaches in Classifying Multi-Temporal LANDSAT Satellite Imagery over an Ephemeral River Area. International Journal of Agricultural and Environmental Information Systems (IJAEIS), 6(4), 83-102.

Tucker, C. J. (1979). Red and photographic infrared linear combinations for monitoring vegetation. Remote Sensing of Environment, 8(2), 127-150.

Turner, B. L., Skole, D., Sanderson, S., Fischer, G., Fresco, L., \& Leemans, R. (1995). Land-use and land-cover change. Science/Research Plan. Global Change Report (Sweden).

Van der Knijff, J., Jones, R., \& Montanarella, L. (2000). Soil erosion risk assessment in Europe: European Soil Bureau, European Commission Belgium.

Varghese, N., \& Singh, N. P. (2016). Linkages between land use changes, desertification and human development in the Thar Desert Region of India. Land Use Policy, 51, 18-25.

Weiers, S., Bock, M., Wissen, M., \& Rossner, G. (2004). Mapping and indicator approaches for the assessment of habitats at different scales using remote sensing and GIS methods. Landscape and Urban Planning, 67(1), 43-65.

Wheeler, D. A. (2007). Why Open Source Software/Free Software (OSS/FS)? Look at the Numbers! http://www.dwheeler.com/oss fs why.html.

Zalidis, G., Stamatiadis, S., Takavakoglou, V., Eskridge, K., \& Misopolinos, N. (2002). Impacts of agricultural practices on soil and water quality in the Mediterranean region and proposed assessment methodology. Agriculture, Ecosystems \& Environment, 88(2), 137-146.

Zhang, J., \& Foody, G. (2001). Fully-fuzzy supervised classification of sub-urban land cover from remotely sensed imagery: statistical and artificial neural network approaches. International journal of remote sensing, 22(4), 615-628.

\section{Authors:}

Dr. Grazia Caradonna ${ }^{1)}$, grazia.caradonna@poliba.it

PhD Antonio Novelli ${ }^{1)}$, antonio.novelli@poliba.it

Prof. Eufemia Tarantino ${ }^{1)}$, eufemia.tarantino@poliba.it

Prof. Raffaela Cefalo ${ }^{2)}$, cefalo@dicar.units.it

Prof. Umberto Fratino ${ }^{1)}$, umberto.fratino@poliba.it

1) DICATECh Politechnic of Bari, Via Orabona 4, 70125, BARI, Italy

${ }^{2)}$ GeoSNav Lab, University of Trieste, p.le Europa 1, 34127, TRIESTE, Italy. 